\section{UMA CRITICA ÀS PRÁTICAS DE CONCILIAÇÃO NA JUSTIÇA DO TRABALHO}

\author{
Jacqueline Samagaia*
}

analítico, busca desvendar as conexões entre as formas de resolução de conflitos jurídicos, presentes em sociedades periféricas como a brasileira, com os interesses do capital internacional. Na realidade brasileira, conforme demonstra sua análise, a perspectiva conciliatória tem se mostrado uma estratégia importante, geralmente alavancada pelas elites hegemônicas no âmbito do Estado e da própria vida política e social para negar os antagonismos e contradições próprios dessa sociedade, os quais se desenvolveram na construção extremamente desigual das classes sociais no país. Nessa direção, tais práticas, conforme demarca o autor, não pertencem exclusivamente ao terreno da cultura trabalhista, pois são constitutivas da própria formação sócio-histórica brasileira. Tais estratégias implicam "mascarar os conflitos de classe”, constituindo, assim, "um verdadeiro estelionato aos direitos dos trabalhadores" (p. 18) e, portanto, uma forma de dar continuidade à exploração intensa do trabalho, devido à condição de economia periférica.

Alguns pontos são ressaltados no estudo, como a construção da Justiça do Trabalho no Brasil no âmbito do sistema jurídico, a qual só veio a se configurar no início do século XX, no contexto do desenvolvimento do mercado de trabalho capitalista. Mais especificamente, em 1915, criou-se um primeiro código do trabalho. Nesse contexto, evidencia-se que a prática de conciliação entre os patrões e empregados, na então indústria que se expandia, era constante. Na primeira Constituição brasileira, conforme demarca o autor, já era prevista a conciliação "como meio precedente a qualquer outro na resolução de conflitos”, o que está bem claro no seu art. 161, no qual constava "que nenhum processo judicial seria instaurado sem que houvesse, antes, tentativa de conciliação entre as partes” (p. 49). Em 1943, essas práticas foram incorporadas na Consolidação das Leis do Trabalho (CLT).

Percebe-se que, aos poucos, a política de conciliação foi sendo incorporada no âmbito do Estado brasileiro, sendo reconhecida dentro 
dos princípios da ordem e da liberdade com um caráter mais operacional. Ultrapassa, então, a forma de pactos, transações e favores, passando a ser concebida na lógica da garantia dos direitos do cidadão. No entanto, conforme pode-se constatar na análise de Hillesheim, em momento de tensões e conflitos por parte da população, sobretudo dos segmentos mais pobres, os recursos da conciliação foram largamente utilizados por uma composição política que unia os interesses das elites oligárquicas (que depois se tornaram urbanas), em estreita articulação com os conservadores e mesmo com os liberais, quando lhes era conveniente manter as formas de poder intactas. Nesse contexto, as reformas tornadas necessárias para o desenvolvimento do país eram pactuadas "pelo alto", excetuando os interesses dos segmentos de escravos, indígenas, caboclos, sertanejos e outros que se encontravam em situação desprivilegiada quanto ao acesso à riqueza socialmente produzida e às instâncias de poder. Desse modo, os resquícios das formas de organização social, política e do próprio trabalho escravo foram se incorporando às relações de trabalho, conforme demonstra o autor no diálogo com autores como Fernandes (2005) e Prado Junior (1971). Essas reflexões levam Hillesheim a afirmar que "a emergência e o desenvolvimento de um regime de classes ocorreram sem que houvesse um rompimento radical com o passado colonial e escravista” (p. 75).

Ao longo dos anos, a Justiça do Trabalho foi, de algum modo, se modificando para atender às demandas e aos conflitos pertinentes ao desenvolvimento capitalista e às tensões entre capital e trabalho. No entanto, seu caráter conciliador, conforme defende o autor, se mantém presente. Nesse caminho, apesar de ganhar reconhecimento por parte dos trabalhadores como espaço de luta na conquista e garantia de direitos relativos ao trabalho, a Justiça do Trabalho mantém a conciliação como um traço permanente, sendo que "o juiz foi sempre esimulado e até mesmo obrigado a utilizar esta via para tentar resolver os litígios envolvendo patrões e empregados" (p. 26).
O processo que se denomina "Mecanismos Alternativos de Resolução de Conflitos" (MARC) foi uma espécie de modelo importado dos Estados Unidos, o qual serviu de referência para práticas conciliatórias no âmbito dos conflitos advindos das relações de trabalho naquele país. Embora haja registro de sua existência em outros países, é muito provável, conforme demonstra o estudo, que tais práticas advenham da marcante influência desse país nas relações econômicas, políticas e culturais em todo o mundo, inclusive nos países da América Latina. A introdução dos MARC ganhou legitimidade sob o argumento do elevado número de processos que abarrotam o sistema judiciário, causando a demora no possível acesso à justiça. Nessa perspectiva, ressalta o autor, o discurso ganha adeptos, inclusive no âmbito dos maiores interessados na justiça do trabalho (os trabalhadores, através de suas representações coletivas organizadas), dando-se enfoque ao desempenho da gestão administrativa e à agilidade da justiça, em prejuízo do debate político sobre os direitos em confronto.

Na segunda parte, intitulada "O judiciário trabalhista como condutor da conciliação: contraditórios processos de garantia de direitos", o autor é movido por uma de suas preocupações iniciais, que tem relação com as consequências ideopolíticas da conciliação trabalhista no contexto da crise estrutural do capital e seus impactos na dinâmica do capitalismo no Brasil. Para isso, buscou construir um caminho teórico-metodológico que permitiu mostrar como as práticas conciliatórias se incorporaram ao funcionamento do sistema judiciário no Brasil, focando, sobretudo, a forma como os MARCs foram estimulados por organismos como o Banco Mundial, nas últimas décadas, no plano das "reformas" propostas para países latino-americanos e caribenhos, significando uma espécie de "reorganização do poder judiciário brasileiro para responder às novas demandas da sociabilidade regida pelo capital” (p. 138).

Nos documentos do Banco Mundial, apresentados e analisados pelo autor, é possí- 
vel perceber uma espécie de estimulo à "modernização do judiciário", justificada através de procedimentos citados como "integração econômica" e "harmonização de leis", vistos como necessários para acomodar novas demandas e se adequar ao contexto internacional (p. 150). "Um poder judiciário, eficaz e funcional é relevante ao desenvolvimento econômico", diz o Banco Mundial (p. 153). Nesse contexto, Hillesheim ressalta a existência de um “padrão internacional” do judiciário para os países latino-americanos, o qual contém uma clara intenção das nações hegemônicas em intensificar os seus domínios sobre as economias periféricas, o que se objetivaria através de novos tratados de comércio, nos quais essas economias tenham funções subsidiárias e marginais. Na perspectiva do autor, a defesa da ampliação dessa estratégia é evidência de que "o direito é um elemento mediador indispensável para a reprodução capitalista” (p. 334).

A análise também revela as intenções dessa instituição em apostar no fortalecimento do poder executivo na periferia do capitalismo, com vistas a garantir as condições de expansão dos mercados capitalistas. O autor segue apontando criticamente a forma como essas proposições foram interpretadas e executadas em países como o Brasil, objetivando-se sob a forma de Medidas Provisórias impostas pelo executivo, as quais tiveram o aval do legislativo, mesmo que se revelassem inconstitucionais. Essa estratégia foi fundamental para garantir a expansão capitalista, supondo-se um judiciário despreparado para fazer face a tão fundamental tarefa.

Os chefes de Estado, nas últimas décadas, têm se apropriado desse discurso, no empenho de tornar as instâncias do poder judiciário mais ágeis, rápidas e funcionais. Embora alguns discursos desses dirigentes busquem justificar essa necessidade em prol do desenvolvimento nacional e da própria crença do cidadão no regime democrático, salienta o autor, com base na análise dos argumentos trazidos por esses sujeitos, que a proposição de um ju- diciário mais célere e eficiente, com estímulo aos mecanismos de conciliação no bojo das formas alternativas de resolução de conflitos, acaba por beneficiar os próprios empregadores, por terem certamente menos dispêndio econômico em face de processos trabalhistas que se arrastam por anos.

As proposições ventiladas nas últimas décadas no Brasil, no âmbito de uma Reforma do Judiciário, chegavam a questionar a própria existência de uma Justiça do Trabalho. Mesmo que defendidas por alguns integrantes do próprio judiciário, essas ideias não tiveram total êxito em função de mobilizações de juízes, advogados e sindicalistas, que organizaram forte resistência, o que demonstra as contradições postas na realidade em questão.

De todo modo, a tendência, conforme aponta Hillesheim, é de que os processos conciliatórios no Brasil, no âmbito da Justiça do Trabalho, tenham se constituído como formas privilegiadas de intermediação dos conflitos entre capital e trabalho. Embora não ocorram percentualmente em maior número nos últimos anos, são objeto de clamor, no sentido de apelo à sua capacidade resolutiva e à manutenção de um clima mais pacifico. Tendo em vista a fragilidade das organizações de resistência dos trabalhadores, essa tática tem demonstrado, em valores absolutos, uma perda quantitativa enorme em termos de direitos dos trabalhadores nas negociações, com transferência de valor do trabalho ao capital. Nesse sentido, Hillesheim dá destaque para o fato de que o uso açodado do instituto da conciliação, no âmbito das relações de trabalho, tem contribuído para intensificar os processos de superexploração do trabalho, nos termos desenvolvidos por Marini (2000). Isso porque, no estabelecimento de pactos conciliatórios com o aval do judiciário trabalhista, os trabalhadores recebem apenas "direitos pela metade", o que garante a transferência de valor produzido no tempo de trabalho necessário - constitutivo, portanto, do fundo de salário -, para o fundo do capital. Isso permite a ampliação do tem- 
po de trabalho excedente e uma apropriação exponencial de valor por parte do capitalista, que se adiciona ao mais-valor já expropriado do trabalhador.

Outro aspecto relevante abordado pelo autor é o fato de que a legitimação da burla de regras que regulam relações formais de trabalho por meio da conciliação, no âmbito do judiciário trabalhista, acaba por provocar um processo que redunda numa informalização de relações consideradas, a priori, como relações formais. Esse fenômeno torna as fronteiras entre trabalho formal e trabalho informal ainda mais tênues, ao mesmo tempo em que corrobora os processos de precarização das condições e das relações de trabalho.

Conforme ressalta o autor, a perspectiva conciliatória vem sendo trazida "como se fosse um antídoto para todos os problemas do judiciário brasileiro", mas, na verdade, tem se constituído como "um instrumento de negação dos direitos" (p. 8), o que tem sido encoberto por um discurso de defesa do amplo acesso à justiça e de celeridade processual, ou seja, de agilidade e seguimento dos processos, re- batendo positivamente no imaginário popular, que vê a demora da justiça como um processo contra seus direitos. No entanto, conforme demonstra o estudo, essa estratégia tem muito mais a contribuir com os efeitos perversos sobre as conquistas históricas dos trabalhadores. Direitos do trabalho, ao serem indiscriminadamente negociados, têm um impacto na vida cultural, filosófica e social dos trabalhadores, colocando em risco as conquistas historicamente alcançadas, alerta o autor.

Recebido para publicação em 19 de novembro de 2017 Aceito em 14 de janeiro de 2018

\section{REFERÊNCIAS}

FERNANDES, Florestan. A revolução burguesa no Brasil: ensaio de interpretação sociológica. 5. ed. São Paulo: Globo, 2005.

HILLESHEIM, Jaime. Conciliação Trabalhista: ofensiva sobre os direitos dos trabalhadores na periferia do capitalismo. Rio de Janeiro: Lumen Juris, 2016.

MARINI, Ruy Mauro. Dialética da Dependência. Rio de Janeiro: Vozes; Buenos Aires: CLACSO, 2000.

PRADO JUNIOR, Caio. Formação do Brasil Contemporâneo. 11. ed. São Paulo: Brasiliense, 1971.

*Jacqueline Samagaia - Doutora em Geografia pela Universidade Federal de Santa Catarina (UFSC). Professora do Curso de Serviço Social da Universidade Federal da Bahia (UFBA). Integra o Núcleo de Pesquisa Trabalho, Trabalhadores e Reprodução Social (CRH, UFBA), desenvolvendo pesquisas na área de trabalho, desigualdade, políticas urbana e habitacional. Universidade Federal da Bahia. Estrada de São Lázaro, 197 - Federação - CEP 40.210-730, Salvador - Bahia - Brasil. jacquegaia@gmail.com 